\title{
Use of Ribotyping To Distinguish Bordetella bronchiseptica Isolates
}

\author{
KAREN B. REGISTER, ${ }^{1 *}$ AGATHA BOISVERT, ${ }^{2}$ AND MARK R. ACKERMANN ${ }^{3}$ \\ Avian and Swine Respiratory Diseases Research Unit, National Animal Disease Center, USDA Agricultural \\ Research Service, ${ }^{1}$ and College of Veterinary Medicine, ${ }^{2}$ and Department of Veterinary Pathology, \\ Iowa State University, ${ }^{3}$ Ames, Iowa 50010
}

\begin{abstract}
A total of 113 Bordetella bronchiseptica strains, isolated from 11 different host species worldwide, were characterized by ribotyping with restriction enzyme $P v u$ II. Sixteen distinct ribotypes were identified, and each ribotype contained five to seven restriction fragments ranging in size from 1.8 to $5.6 \mathrm{~kb}$. Approximately $88 \%$ of the swine isolates were identified as ribotype 3 strains. Isolates from dogs also displayed little variation; $74.1 \%$ were found to be ribotype 4 strains. Strains obtained from the remaining nine host species belonged to 15 different ribotypes. There was no association between geographic location and ribotype. The technique which we used may be useful for epidemiologic studies in which the transmission of $B$. bronchiseptica, both within and between species, is investigated.
\end{abstract}

Bordetella bronchiseptica is a common pathogen of the upper respiratory tract in a number of mammalian species. It causes atrophic rhinitis and pneumonia in swine, acute tracheobronchitis in dogs, and bronchopneumonia in a variety of laboratory animals, including rabbits, guinea pigs, rats, mice, cats, and nonhuman primates (8). On rare occasions, $B$. bronchiseptica is also associated with sinusitis, tracheobronchitis, pneumonia, and septicemia in humans $(5,10,28)$.

Transmission of $B$. bronchiseptica is thought to occur primarily through aerosol droplets and direct contact between infected and noninfected animals (7). Cross-species transmission has been proposed as one mechanism of spread, but the frequency and importance of this process in the dissemination of disease are not known $(4,7)$. Since $B$. bronchiseptica is able to survive and even grow under nutrient-poor conditions, it has also been postulated that soil and water environments act as natural reservoirs for infection $(15,21,22)$. However, there have been few epidemiologic studies which have addressed the mechanisms of transmission of this organism.

A major obstacle to understanding the natural transmission patterns of $B$. bronchiseptica is the lack of a simple and reliable typing system for classification of various isolates. Some investigators have attempted to utilize phenotypic properties of $B$. bronchiseptica to distinguish between isolates from different hosts. Pederson (19) conducted a serotyping study in which it was demonstrated that there is heterogeneity among pig, cat, rabbit, mouse, and rat isolates. However, the usefulness of serotype-specific antisera for establishing host specificity remains questionable, since only one or a few isolates of each species were tested. Although several other workers have also demonstrated that there is an association between particular phenotypes and host species $(3,6,17,23)$, a serious limitation of such approaches for classification of strains is that phenotypic traits of bacteria can vary under different growth conditions. This is especially true for Bordetella species, which undergo extensive alterations in surface proteins and biological characteristics during culture in vitro $(1,20)$.

Multilocus enzyme electrophoresis (MLEE) has also been used to determine the degree of variation in B. bronchiseptica strains (17). Like serotyping, this technique depends upon

\footnotetext{
* Corresponding author. Mailing address: Swine Respiratory Diseases Project, USDA ARS National Animal Disease Center, P.O. Box 70, 2300 Dayton Road, Ames, IA 50010. Phone: (515) 239-8275. Fax: (515) 239-8458. E-mail: kregiste@nadc.ars.usda.gov.
}

phenotypic expression of genetic loci. However, expression of the metabolic enzymes upon which classification is based is thought to be more stable than expression of surface antigens (24). In a separate study, evidence supporting the stability of Bordetella pertussis electrophoretic types (ETs) in vitro was obtained under conditions that induced a variety of other phenotypic changes (18). It has been assumed that $B$. bronchiseptica ETs are similarly invariant, although this has not been tested experimentally. MLEE has the additional disadvantage of being technically cumbersome, since several different buffer systems must be tested for optimal results and numerous staining solutions are required (24). Depending on the degree of polymorphism, several hundred gels may be necessary for an analysis of 100 isolates (24).

Methods that rely on analysis of stable genetic elements are likely to be more reproducible for classification of bacterial strains than expression-based techniques. However, the utility of such techniques for classification of bordetellas is questionable, since a comparison of chromosomal DNA sequences based on reassociation reactions indicated that $B$. pertussis, ordetella parapertussis, and $B$. bronchiseptica are closely related and can be considered members of a single genomic group (13). The results of the same study also suggested that the genetic variance among $B$. bronchiseptica isolates from three different host species was minimal, although only a few strains were analyzed. In addition, this technique may not be sufficiently discriminatory to distinguish between closely related populations, since the level of experimental error can be as high as $10 \%(24,25)$. Conversely, the results of a study in which pulsed-field gel electrophoresis was used revealed three distinct DNA types among the eight $B$. bronchiseptica isolates tested (12). Since the origin of these strains was not given, it is unclear whether there was any correlation between DNA type and host species. The fragmentary and conflicting data currently available do not clearly establish whether the level of sequence variability among $B$. bronchiseptica isolates is sufficient to permit placing strains into different groups.

Analysis of restriction fragment length polymorphisms of rRNA genes, or ribotyping, is a widely used technique for differentiating bacterial strains $(9,27)$. The goal of our study was to determine whether this technique can be used to differentiate isolates of $B$. bronchiseptica obtained from a variety of host species. 
TABLE 1. B. bronchiseptica strains used

\begin{tabular}{|c|c|c|c|c|}
\hline Strain & Host & Country of origin & Ribotype & $\mathrm{ET}^{a}$ \\
\hline MBORD545 & Pig & The Netherlands & 3 & $1 \mathrm{a}$ \\
\hline MBORD553 & Pig & United Kingdom & 1 & $1 \mathrm{a}$ \\
\hline MBORD603 & Pig & Canada & 3 & 1 \\
\hline MBORD605 & Pig & Canada & 3 & 1 \\
\hline MBORD606 & Pig & Canada & 3 & 1 \\
\hline MBORD676 & Pig & Australia & 2 & 3 \\
\hline MBORD677 & Pig & Australia & 3 & 3 \\
\hline MBORD688 & Pig & United States & 3 & 8 \\
\hline MBORD790 & Pig & The Netherlands & 3 & 1 \\
\hline MBORD791 & Pig & The Netherlands & 3 & 1 \\
\hline MBORD792 & Pig & The Netherlands & 3 & 1 \\
\hline MBORD793 & Pig & The Netherlands & 3 & 1 \\
\hline MBORD795 & Pig & The Netherlands & 3 & 1 \\
\hline MBORD796 & Pig & The Netherlands & 3 & 1 \\
\hline MBORD797 & Pig & The Netherlands & 3 & 1 \\
\hline MBORD798 & Pig & The Netherlands & 3 & 1 \\
\hline MBORD800 & Pig & The Netherlands & 3 & 1 \\
\hline MBORD801 & Pig & The Netherlands & 3 & 1 \\
\hline MBORD802 & Pig & The Netherlands & 3 & 1 \\
\hline MBORD803 & Pig & The Netherlands & 3 & 1 \\
\hline MBORD804 & Pig & The Netherlands & 3 & 1 \\
\hline MBORD805 & Pig & The Netherlands & 3 & 1 \\
\hline MBORD846 & Pig & Switzerland & 2 & 1 \\
\hline MBORD847 & Pig & Switzerland & 2 & 1 \\
\hline MBORD849 & Pig & The Netherlands & 3 & 1 \\
\hline MBORD850 & Pig & The Netherlands & 3 & 1 \\
\hline MBORD853 & Pig & Ireland & 3 & 1 \\
\hline MBORD976 & Pig & The Netherlands & 3 & 1 \\
\hline MBORD979 & Pig & The Netherlands & 3 & 1 \\
\hline MBORD980 & Pig & The Netherlands & 3 & 1 \\
\hline B58 & Pig & Hungary & 3 & $\mathrm{ND}^{b}$ \\
\hline B65 & Pig & Hungary & 3 & ND \\
\hline 5203 & Pig & Hungary & 3 & ND \\
\hline MBORD590 & Dog & United States & 4 & 6 \\
\hline MBORD591 & Dog & United States & 13 & 14 \\
\hline MBORD592 & Dog & United States & 4 & 6 \\
\hline MBORD594 & Dog & United States & 4 & 6 \\
\hline MBORD595 & Dog & United States & 5 & 4 \\
\hline MBORD596 & Dog & United States & 4 & 6 \\
\hline MBORD599 & Dog & United States & 4 & 6 \\
\hline MBORD600 & Dog & United States & 4 & 6 \\
\hline MBORD601 & Dog & United States & 4 & 6 \\
\hline MBORD602 & Dog & United States & 4 & 6 \\
\hline MBORD685 & Dog & United States & 3 & 1 \\
\hline MBORD686 & Dog & United States & 3 & 1 \\
\hline MBORD732 & Dog & Denmark & 4 & 8 \\
\hline MBORD748 & Dog & Denmark & 4 & 8 \\
\hline MBORD749 & Dog & Denmark & 4 & 16 \\
\hline MBORD750 & Dog & Denmark & 4 & 16 \\
\hline MBORD783 & Dog & The Netherlands & 4 & 16 \\
\hline MBORD785 & Dog & The Netherlands & 3 & 1 \\
\hline MBORD786 & Dog & The Netherlands & 4 & 8 \\
\hline MBORD787 & Dog & The Netherlands & 4 & 16 \\
\hline MBORD788 & Dog & The Netherlands & 13 & 8 \\
\hline MBORD827 & Dog & Switzerland & 4 & 6 \\
\hline MBORD839 & Dog & Switzerland & 4 & 8 \\
\hline MBORD843 & Dog & Switzerland & 4 & 6 \\
\hline MBORD965 & Dog & The Netherlands & 4 & 1 \\
\hline MBORD966 & Dog & The Netherlands & 3 & 1 \\
\hline MBORD967 & Dog & The Netherlands & 4 & 8 \\
\hline MBORD671 & Rabbit & United States & 9 & ND \\
\hline MBORD704 & Rabbit & United States & 2 & 1 \\
\hline MBORD705 & Rabbit & United States & 5 & ND \\
\hline MBORD730 & Rabbit & Denmark & 9 & 16 \\
\hline MBORD784 & Rabbit & The Netherlands & 3 & 1 \\
\hline MBORD823 & Rabbit & Switzerland & 3 & 1 \\
\hline MBORD828 & Rabbit & Switzerland & 3 & 1 \\
\hline
\end{tabular}

TABLE 1 -Continued

\begin{tabular}{|c|c|c|c|c|}
\hline Strain & Host & Country of origin & Ribotype & $\mathrm{ET}^{a}$ \\
\hline MBORD831 & Rabbit & Switzerland & 9 & 16 \\
\hline MBORD833 & Rabbit & Switzerland & 12 & 1 \\
\hline MBORD834 & Rabbit & Switzerland & 12 & 1 \\
\hline MBORD835 & Rabbit & Switzerland & 9 & 16 \\
\hline MBORD836 & Rabbit & Switzerland & 3 & 1 \\
\hline MBORD837 & Rabbit & Switzerland & 9 & 16 \\
\hline MBORD838 & Rabbit & Switzerland & 12 & 1 \\
\hline MBORD971 & Rabbit & The Netherlands & 9 & 16 \\
\hline MBORD972 & Rabbit & The Netherlands & 3 & 1 \\
\hline MBORD981 & Rabbit & The Netherlands & 3 & 1 \\
\hline MBORD629 & Cat & United States & 4 & 16 \\
\hline MBORD630 & Cat & United States & 4 & 16 \\
\hline MBORD631 & Cat & United States & 4 & 16 \\
\hline MBORD635 & Cat & United States & 2 & 1 \\
\hline MBORD723 & Cat & Denmark & 4 & 16 \\
\hline MBORD733 & Cat & Denmark & 4 & 16 \\
\hline MBORD745 & Cat & Denmark & 3 & 1 \\
\hline MBORD782 & Cat & The Netherlands & 13 & ND \\
\hline MBORD968 & Cat & The Netherlands & 4 & 16 \\
\hline MBORD970 & Cat & The Netherlands & 13 & 16 \\
\hline MBORD627 & Guinea pig & United States & 9 & 16 \\
\hline MBORD665 & Guinea pig & United States & 11 & 16 \\
\hline MBORD666 & Guinea pig & United States & 12 & 16 \\
\hline MBORD668 & Guinea pig & United States & 12 & 16 \\
\hline MBORD669 & Guinea pig & United States & 3 & 16 \\
\hline MBORD670 & Guinea pig & United States & 2 & 3 \\
\hline MBORD673 & Guinea pig & Germany & 3 & 3 \\
\hline MBORD674 & Guinea pig & Germany & 12 & 1 \\
\hline MBORD762 & Guinea pig & Ireland & 10 & 1 \\
\hline MBORD854 & Guinea pig & Switzerland & 10 & 1 \\
\hline MBORD624 & Horse & United States & 7 & 16 \\
\hline MBORD628 & Horse & United States & 4 & 16 \\
\hline MBORD632 & Horse & United States & 9 & 16 \\
\hline MBORD633 & Horse & United States & 4 & 16 \\
\hline MBORD731 & Horse & Denmark & 8 & ND \\
\hline MBORD982 & Horse & The Netherlands & 8 & ND \\
\hline MBORD983 & Horse & The Netherlands & 4 & ND \\
\hline MBORD681 & Koala & Australia & 6 & 1 \\
\hline MBORD698 & Koala & Australia & 6 & 1 \\
\hline MBORD700 & Koala & Australia & 6 & 1 \\
\hline MBORD675 & Human & Germany & 14 & 14 \\
\hline St. Louis & Human & United States & 15 & ND \\
\hline MBORD707 & Turkey & United States & 16 & 1 \\
\hline MBORD901 & Turkey & Germany & 15 & ND \\
\hline MBORD625 & Rat & United States & 2 & 16 \\
\hline MBORD626 & Leopard & United States & 6 & 16 \\
\hline
\end{tabular}

${ }^{a}$ ET as described by Musser et al. (17).

${ }^{b} \mathrm{ND}$, not determined.

\section{MATERIALS AND METHODS}

Strains. A total of 113 B. bronchiseptica isolates were examined. Strain St. Louis was provided by Tom Milligan, St. Louis University Hospital, St. Louis, Mo., and was identified on the basis of Gram staining, colony morphology, and the results of standard biochemical tests. Strains B58, B65, and 5203 (14) were obtained from Tibor Magyar, Veterinary Medical Research Institute of the Hungarian Academy of Sciences, Budapest, Hungary. All of the remaining strains were originally characterized by workers in the laboratory of James Musser (17) and were generously provided by David Dyer, University of Oklahoma, Oklahoma City. The strains were obtained from a variety of host species and from geographically diverse locations (Table 1). They included 33 swine isolates, $27 \mathrm{dog}$ isolates, 17 rabbit isolates, 10 cat isolates, 10 guinea pig isolates, 


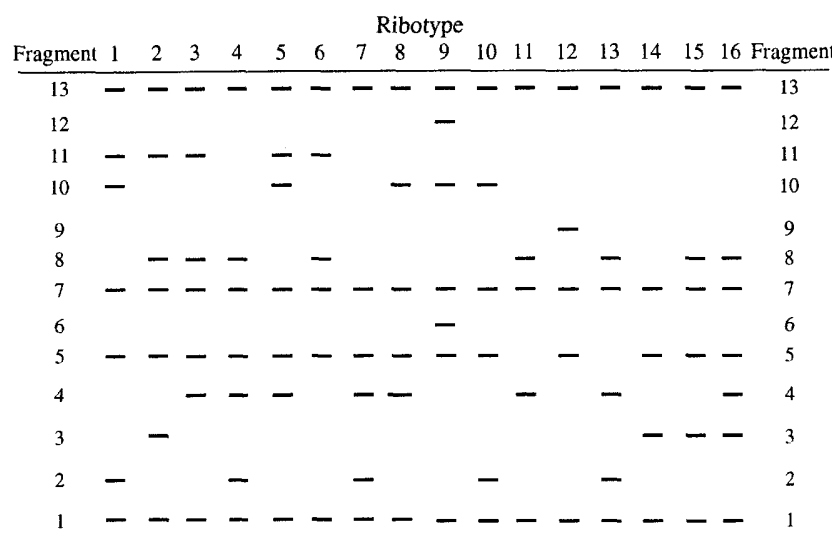

FIG. 1. Ribotype patterns observed following digestion of $B$. bronchiseptica chromosomal DNAs with PvuII. A total of 13 unique fragments were observed, and these fragments ranged in size from $1.8 \mathrm{~kb}$ (fragment 1 ) to $5.6 \mathrm{~kb}$ (fragment 10 ).

7 horse isolates, 3 koala isolates, 2 turkey isolates, 2 human isolates, 1 leopard isolate, and 1 rat isolate. All of the strains were cultivated for 36 to $48 \mathrm{~h}$ at $37^{\circ} \mathrm{C}$ on Bordet-Gengou medium supplemented with $15 \%$ defibrinated sheep blood.

Purification of chromosomal DNA. A single loopful of bacterial growth was resuspended in $0.5 \mathrm{~m}$ ] of phosphate-buffered saline and washed once. Genomic DNA was purified by using a commercially available kit as recommended by the manufacturer (QIAGEN, Inc., Chatsworth, Calif.). Final DNA precipitates were dissolved by overnight incubation at $55^{\circ} \mathrm{C}$ in $10 \mathrm{mM}$ Tris-1 $\mathrm{mM}$ EDTA (pH 8.0). The concentrations and purities of DNA preparations were assessed spectrophotometrically.

Restriction endonuclease digestion and gel electrophoresis. Several restriction enzymes were used in preliminary experiments to identify one or more enzymes that gave optimal results. A 3- $\mu \mathrm{g}$ portion of DNA was digested with $10 \mathrm{U}$ of either EcoRI, SalI, PstI, HinfI, $A l u \mathrm{I}$, or $P v u \mathrm{II}$ at $37^{\circ} \mathrm{C}$ overnight. After incubation, loading dye $(0.25 \%$ bromphenol blue, $30 \%$ glycerol) was added, and samples were electrophoresed in $0.6 \%$ agarose gels containing $0.5 \mu \mathrm{g}$ of ethidium bromide per $\mathrm{ml}$ in Tris-borate buffer $(89 \mathrm{mM}$ Tris, $89 \mathrm{mM}$ boric acid, $2 \mathrm{mM}$ disodium EDTA). Following electrophoresis, DNA was visualized by UV illumination and photographed with type 57 Polaroid film to confirm that the high-molecular-weight nucleic acid was completely digested and to establish that visually equivalent amounts of DNA were present in the lanes. A 1- to 12-kb DNA ladder (Boehringer Mannheim) was included in an adjacent lane on each gel, and the migration distances of the fragments were used to prepare a standard curve. The molecular masses of $B$. bronchiseptica fragments were determined by plotting the migration of the fragments on standard curves.

Southern blots. After electrophoresis, DNA was partially depurinated by incubating it in $250 \mathrm{mM} \mathrm{HCl}$ for $10 \mathrm{~min}$ and then was denatured in $0.5 \mathrm{~N}$ $\mathrm{NaOH}-1.5 \mathrm{M} \mathrm{NaCl}$. The gel was neutralized in $1.0 \mathrm{M}$ Tris $(\mathrm{pH} 8.0)-1.5 \mathrm{M} \mathrm{NaCl}$. Restriction fragments were transferred to charged nylon membranes by overnight capillary transfer by using $10 \times \mathrm{SSC}(1 \times \mathrm{SSC}$ is $150 \mathrm{mM} \mathrm{NaCl}$ plus $15 \mathrm{mM}$

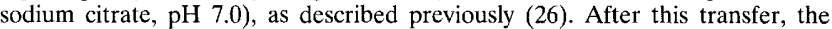
DNA was fixed to the membranes by UV cross-linking with a UV Stratalinker (Stratagene, La Jolla, Calif.) as recommended by the manufacturer.

Ribotyping. Plasmid pRRNB (generously provided by Kenneth Pidcock, Wilkes University, Wilkes-Barre, Pa.) was digoxigenin labeled by the random priming method (2) and was hybridized to membrane-bound chromosomal DNA digests. This plasmid contains a 5.4-kb fragment of the Escherichia coli rRNA operon $r n B(16)$. Prehybridization and hybridization were carried out at $42^{\circ} \mathrm{C}$, as described previously (2), in a maleic acid-based buffer. The hybridization solution contained $10 \mathrm{ng}$ of digoxigenin-labeled probe per $\mathrm{ml}$ in $5 \times \mathrm{SSC}-50 \%$ formamide $-0.02 \%$ sodium dodecyl sulfate (SDS) $-0.1 \% \mathrm{~N}$-lauroylsarcosine $-2 \%$ blocking reagent- $20 \mathrm{mM}$ sodium maleate. Following removal from the hybridization solution, the membranes were washed twice for $5 \mathrm{~min}$ at room temperature in $2 \times \mathrm{SSC}$ containing $0.1 \%$ SDS and twice for $15 \mathrm{~min}$ at $65^{\circ} \mathrm{C}$ in $0.5 \times \mathrm{SSC}$ containing $0.1 \%$ SDS. Bound probe was detected by using an anti-digoxigeninalkaline phosphatase antibody conjugate and LumiPhos as described previously (2). Membranes were sealed in plastic bags prior to exposure to Kodak XAR5 film. Following detection of bound $\mathrm{pRRNB}$, the membranes were stripped of the probe by incubating them at $37^{\circ} \mathrm{C}$ for $30 \mathrm{~min}$ in $0.2 \mathrm{~N} \mathrm{NaOH}-0.1 \% \mathrm{SDS}$. The membranes were subsequently hybridized with digoxigenin-labeled pUC19, the vector containing the $r m B$ fragment, to verify that positive hybridization signals were due to the fragment and not to vector sequences.

Data analysis. Ribotypes were designated by Arabic numerals, which were assigned as the ribotypes were encountered. Strains that exhibited single band differences were assigned to different ribotypes. The discriminatory power of ribotyping for isolates derived from various groups of host species was defined by calculating discrimination indices as described by Hunter and Gaston (11).

\section{RESULTS AND DISCUSSION}

Ribotype identification. The initial experiments were performed with a subset of $B$. bronchiseptica strains to identify a restriction enzyme that provided multiple, easily defined band patterns. DNAs from 10 strains representing the pig, dog, and rabbit isolates were digested with EcoRI, SalI, PstI, HinfI, AluI, or PvuII, and this was followed by Southern blotting and hybridization with pRRNB. PvuII was found to provide the largest number of easily separated fragments and was used for the remainder of the study.

Sixteen distinct band patterns resulting from different combinations of 13 unique restriction fragments were identified when the 113 strains listed in Table 1 were examined. A representation of each ribotype pattern is shown in Fig. 1. Each ribotype consisted of five to seven fragments that ranged in size from $1.8 \mathrm{~kb}$ (fragment 1) to $5.6 \mathrm{~kb}$ (fragment 13). Fragments 13,7 , and 1 were conserved in all strains. Examples of 7 of the 16 band patterns are shown in Fig. 2 .

The band patterns representing ribotypes 3 and 4 were the most commonly observed band patterns (37.2 and $25.7 \%$ of all isolates, respectively). The remainder of the strains were scattered among 14 other ribotypes, with no more than $7.1 \%$ of the strains in any single group.

Approximately one-half of the strains used in this study were subjected to repeat analysis to assess the reproducibility of ribotyping. The pattern obtained was always identical to the original pattern for each strain (data not shown). In addition, at least one strain representing each ribotype has been used repeatedly as a type standard in our laboratory during the past 1 year, with invariant results.

Distribution of host species within ribotypes. Table 2 shows the distribution of host species within ribotypes. A total of $87.9 \%$ of the swine strains were ribotype 3 strains; the remaining swine isolates were ribotype 1 or 2 strains. Conversely, $69.0 \%$ of the strains identified as ribotype 3 isolates were obtained from pigs. Ribotype 3 also included a minority of the strains from dogs, cats, and guinea pigs. In addition, ribotype 3 was one of the two predominant groups containing rabbit isolates.

Strains isolated from dogs were also highly associated with a single ribotype; $74.1 \%$ of the isolates were ribotype 4 strains, while the remaining isolates tested were ribotype 3,5 , or 13 strains. Dog strains accounted for $69.0 \%$ of the ribotype 4 isolates; the remainder of the strains in this group were originally isolated from either cats or horses.

All of the strains isolated from koalas were ribotype 6 strains. Since only three isolates from this host were available

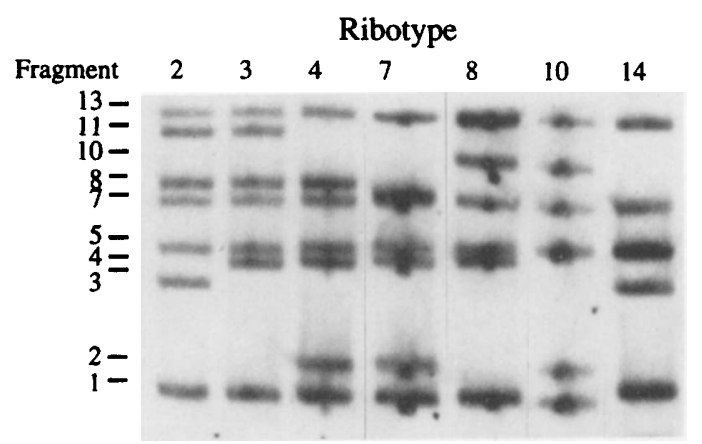

FIG. 2. Lumigraph showing the results of one ribotyping experiment in which seven different ribotypes were identified. B. bronchiseptica chromosomal DNAs were digested with $P v u \mathrm{II}$. 
TABLE 2. Distribution of host species within ribotypes

\begin{tabular}{|c|c|c|c|c|c|c|c|c|c|c|c|c|}
\hline \multirow{2}{*}{ Ribotype } & \multicolumn{11}{|c|}{ No. of strains from the following hosts } & \multirow{2}{*}{$\begin{array}{l}\text { Total no. of } \\
\text { strains }\end{array}$} \\
\hline & Pig & Dog & Rabbit & Cat & Guinea pig & Horse & Koala & Human & Turkey & Rat & Leopard & \\
\hline 1 & 1 & & & & & & & & & & & 1 \\
\hline 2 & 3 & & 1 & 1 & 1 & & & & & 1 & & 7 \\
\hline 3 & 29 & 4 & 6 & 1 & 2 & & & & & & & 42 \\
\hline 4 & & 20 & & 6 & & 3 & & & & & & 29 \\
\hline 5 & & 1 & 1 & & & & & & & & & 2 \\
\hline 6 & & & & & & & 3 & & & & 1 & 4 \\
\hline 7 & & & & & & 1 & & & & & & 1 \\
\hline 8 & & & & & & 2 & & & & & & 2 \\
\hline 9 & & & 6 & & 1 & 1 & & & & & & 8 \\
\hline 10 & & & & & 2 & & & & & & & 2 \\
\hline 11 & & & & & 1 & & & & & & & 1 \\
\hline 12 & & & 3 & & 3 & & & & & & & 6 \\
\hline 13 & & 2 & & 2 & & & & & & & & 4 \\
\hline 14 & & & & & & & & 1 & & & & 1 \\
\hline 15 & & & & & & & & 1 & 1 & & & 2 \\
\hline 16 & & & & & & & & & 1 & & & 1 \\
\hline Total & 33 & 27 & 17 & 10 & 10 & 7 & 3 & 2 & 2 & 1 & 1 & \\
\hline
\end{tabular}

for testing, there are not enough data to establish that there is a strong association between koala isolates and ribotype 6 .

There was no obvious correlation between any other host species and a single ribotype pattern.

Geographic distribution of ribotypes. It is evident from the information presented in Table 1 that a number of different ribotypes occur in most of the countries represented in this study. Thus, there is no obvious association between ribotype and geographic location. Although only a single ribotype was found among the isolates from Hungary and Canada, only a few isolates from these countries were available for testing.

Comparison of ribotyping with MLEE. MLEE, a technique that detects mobility variants of metabolic enzymes, is the only method that has been used previously to determine the degree of variation in a large number of $B$. bronchiseptica strains (17). In the study of Musser et al. (17), 303 isolates from 11 different host species were classified into 21 different groups or ETs. Since this technique could prove to be useful for epidemiologic purposes, we used the data of Musser et al. (17) to compare the discriminatory power of MLEE with that of ribotyping.

When ribotyping data derived from the 113 strains used in this study were analyzed, a discrimination index of 0.786 was obtained (Table 3 ). This value indicates that two randomly isolated strains would fall into different ribotypes $78.6 \%$ of the time. A method is considered sufficiently discriminatory for typing purposes if a discrimination index of 0.900 or greater is obtained (11). The discrimination index for MLEE, based on the data provided in the study of Musser et al. (17), is 0.567 . Although neither the ribotyping method nor the MLEE method yielded a level of confidence suitable for epidemiologic studies, ribotyping is more discriminatory. It appeared that the strong association of pig isolates and dog isolates with ribotypes 3 and 4, respectively (Table 2), significantly impaired the ability of the ribotyping method to differentiate random isolates. Similarly, MLEE revealed low levels of interspecies clonal diversity with pig and dog isolates (17). The discrimination indices for strains isolated from only these two species were also very low (Table 3 ). Therefore, we calculated discrimination indices for ribotyping and MLEE based on the results obtained with isolates from all of the host species except pigs and dogs. For ribotyping, the index was high enough (0.905) that this method can be used with confidence to monitor transmission patterns of $B$. bronchiseptica strains in hosts other than pigs and dogs. Even when isolates from pigs and dogs were omitted from the analysis, the discriminatory ability of MLEE was not sufficient to propose that this method could be used as an epidemiologic tool (Table 3).

The superior ability of ribotyping for distinguishing $B$. bronchiseptica isolates is further illustrated in Table 4. The ETs for 102 of the 113 strains used for ribotyping were obtained from the report of Musser et al. (17), and their distribution within ribotypes was determined. The strains in the two most common ETs, ETs 1 and 16, could be further differentiated into seven or eight additional groups when ribotyping was employed. In con-

TABLE 3. Discrimination indices for ribotyping and MLEE of $B$. bronchiseptica isolates ${ }^{a}$

\begin{tabular}{|c|c|c|c|c|}
\hline $\begin{array}{l}\text { Typing } \\
\text { method }\end{array}$ & $\begin{array}{l}\text { No. of } \\
\text { host } \\
\text { species }\end{array}$ & $\begin{array}{l}\text { No. of } \\
\text { types }\end{array}$ & $\begin{array}{l}\text { No. of isolates in } \\
\text { different types }\end{array}$ & $\begin{array}{l}\text { Discrim- } \\
\text { ination } \\
\text { index }\end{array}$ \\
\hline \multirow[t]{3}{*}{ Ribotyping } & $11^{b}$ & 16 & $\begin{array}{l}1,7,42,29,2,4,1,2,8,2, \\
\quad 1,6,4,1,2,1\end{array}$ & 0.786 \\
\hline & $2^{c}$ & 6 & $1,3,33,20,1,2$ & 0.592 \\
\hline & $9^{d}$ & 15 & $\begin{array}{l}4,9,9,1,4,1,2,8,2,1,6 \\
2,1,2,1\end{array}$ & 0.905 \\
\hline \multirow[t]{3}{*}{ MLEE } & $11^{b}$ & 21 & $\begin{array}{l}193,1,4,7,1,32,1,1,1 \\
1,1,1,7,7,1,38,1,1 \\
1,1,2\end{array}$ & 0.567 \\
\hline & $2^{c}$ & 15 & $\begin{array}{c}169,3,6,1,30,1,1,1,4 \\
3,1,1,1,1,2\end{array}$ & 0.418 \\
\hline & $9^{d}$ & 13 & $\begin{array}{l}24,1,1,1,2,1,1,1,3,4 \\
\quad 1,37,1\end{array}$ & 0.683 \\
\hline
\end{tabular}

${ }^{a}$ Ribotypes were determined in this study. MLEE indices were calculated by using the data of Musser et al. (17).

${ }^{b}$ Strains from all host species were tested.

$c$ Only pig and dog isolates were tested.

${ }^{d}$ Strains from all host species except pigs and dogs were tested. 
TABLE 4. Distribution of MLEE ETs within ribotypes ${ }^{a}$

\begin{tabular}{|c|c|c|c|c|c|c|c|}
\hline \multirow{2}{*}{ Ribotype } & \multicolumn{7}{|c|}{ No. of strains with the following MLEE ETs } \\
\hline & 1 & 3 & 4 & 6 & 8 & 14 & 16 \\
\hline 1 & 1 & & & & & & \\
\hline 2 & 4 & 2 & & & & & 1 \\
\hline 3 & 35 & 2 & & & 1 & & 1 \\
\hline 4 & 1 & & & 10 & 5 & & 12 \\
\hline 5 & & & 1 & & & & \\
\hline 6 & 3 & & & & & & 1 \\
\hline 7 & & & & & & & 1 \\
\hline 8 & & & & & & & \\
\hline 9 & & & & & & & 7 \\
\hline 10 & 2 & & & & & & \\
\hline 11 & & & & & & & 1 \\
\hline 12 & 4 & & & & & & 2 \\
\hline 13 & & & & & 1 & 1 & 1 \\
\hline 14 & & & & & & 1 & \\
\hline 15 & & & & & & & \\
\hline 16 & 1 & & & & & & \\
\hline Total & 51 & 4 & 1 & 10 & 7 & 2 & 27 \\
\hline
\end{tabular}

${ }^{a}$ The MLEE ETs for 102 of the 113 strains used for ribotyping were obtained from the report of Musser et al. (17).

trast, the two most prevalent ribotypes, ribotypes 3 and 4, were separated into only three additional groups when MLEE results were considered.

The data in Table 4 also illustrate that a combination of ribotyping and MLEE can be used to define 26 distinct groups for the 102 isolates included in both studies, compared with only 7 MLEE groups and 14 ribotypes. Therefore, the use of these two methods together is likely to provide superior discriminatory power compared with ribotyping alone. The calculated discrimination index for MLEE combined with ribotyping was 0.853 , indicating that the combination of typing methods is superior to ribotyping alone. However, this combination of techniques cannot be recommended for routine typing of $B$. bronchiseptica isolates due to the labor-intensive nature of MLEE and to the fact that the discrimination index still falls short of the value recommended as acceptable for a typing method (11).

Ribotyping has been used by many investigators for determining the molecular epidemiology of genetically diverse organisms $(9,27)$. Our data demonstrate that there is sufficient diversity within $B$. bronchiseptica to allow grouping of isolates into distinct types. Based on the distribution of ribotypes within host species, we were unable to demonstrate sufficient diversity within isolates from pigs and dogs to permit documentation of transmission patterns in homologous species. The results of MLEE also indicated that strains from pigs and dogs are highly clonal (17). This lack of genetic divergence may be useful in some situations. If an isolate of unknown origin is identified as a ribotype 3 strain, there is a strong probability that it originated in swine. Isolates with a ribotype 4 pattern are likely to have arisen in dogs. The small number of isolates from other hosts that also produced these ribotype patterns may be the result of cross-species transmission. However, any conclusions concerning the origin of isolates reached on the basis of identification as ribotype 3 or 4 strains must be considered tentative.

Our data also indicate that ribotyping may be an effective tool for molecular epidemiology in hosts other than pigs and dogs. While ribotyping requires the capability to perform agarose gel electrophoresis and Southern blotting, it is not a technically difficult procedure. Utilization of a digoxigenin-labeled probe, rather than a probe labeled radioactively, facilitates the use of this method since digoxigenin-labeled probes can be reused for 1 year or more and no special safety precautions or disposal procedures are required.

\section{ACKNOWLEDGMENTS}

We thank David Dyer, Tibor Magyar, and Tom Milligan for kindly providing the strains used in this study. We are indebted to Kenneth Pidcock for providing pRRNB and helpful advice.

A.B. was supported by the Merck Veterinary Scholars Program.

\section{REFERENCES}

1. Bemis, D. A., and E. H. Burns, Jr. 1993. Bordetella, p. 210-215. In C. L. Gyles and C. O. Thoen (ed.), Pathogenesis of bacterial infections in animals. Iowa State University Press, Ames.

2. Boehringer Mannheim Corporation. 1992. The Genius system user's guide for filter hybridization. Boehringer Mannheim Corporation, Indianapolis, Ind.

3. Collings, L. A., and J. M. Rutter. 1985. Virulence of Bordetella bronchiseptica in the porcine respiratory tract. J. Med. Microbiol. 19:247-255.

4. De Jong, M. F. 1992. (Progressive) atrophic rhinitis, p. 414-435. In A. D Leman, B. E. Straw, W. L. Mengeling, S. D'Allaire, and D. J. Taylor (ed.) Diseases of swine. Iowa State University Press, Ames.

5. Delafuente, J., C. Albo, A. Rodriguez, B. Sopena, and C. Martinez. 1994 Bordetella bronchiseptica pneumonia in a patient with AIDS. Thorax 49:719720 .

6. Giardina, P. C., L.-A. Foster, J. M. Musser, B. J. Akerley, J. F. Miller, and D. W. Dyer. 1995. bvg repression of alcaligin synthesis in Bordetella bronchiseptica is associated with phylogenetic lineage. J. Bacteriol. 177:6058-6063.

7. Giles, C. J. 1992. Bordetellosis, p. 436-445. In A. D. Leman, B. E. Straw W. L. Mengeling, S. D'Allaire, and D. J. Taylor (ed.), Diseases of swine. Iowa State University Press, Ames.

8. Goodnow, R. A. 1980. Biology of Bordetella bronchiseptica. Microbiol. Rev. 44:722-738.

9. Grimont, F., and P. A. D. Grimont. 1986. Ribosomal ribonucleic acid gene restriction patterns as potential taxonomic tools. Ann. Inst. Pasteur Microbiol. 137:165-175.

10. Gueirard, P., C. Weber, A. Le Coustumier, and N. Guiso. 1995. Human Bordetella bronchiseptica infection related to contact with infected animals: persistence of bacteria in host. J. Clin. Microbiol. 33:2002-2006.

11. Hunter, P. R., and M. A. Gaston. 1988. Numerical index of the discriminatory ability of typing systems: an application of Simpson's index of diversity. J. Clin. Microbiol. 26:2465-2466.

12. Khattak, M. N., and R. C. Mathews. 1993. Genetic relatedness of Bordetella species as determined by macrorestriction digests resolved by pulsed-field gel electrophoresis. Int. J. Syst. Bacteriol. 43:659-664.

13. Kloos, W. E., N. Mohapatra, W. J. Dobrogosz, J. W. Ezzel, and C. R. Manclark. 1981. Deoxyribonucleotide sequence relationships among Bordetella species. Int. J. Syst. Bacteriol. 31:173-176.

14. Magyar, T., N. Chanter, A. J. Lax, J. M. Rutter, and G. A. Hall. 1988. The pathogenesis of turbinate atrophy in pigs caused by Bordetella bronchiseptica. Vet. Microbiol. 18:135-146.

15. Mitscherlich, E., and E. H. Marth. 1984. Bacteria and rickettsiae important in human and animal health, p. 45-47. In Microbial survival in the environment. Springer-Verlag, Berlin, Germany.

16. Moser, C. A., R. L. Stull, and K. A. Pidcock. 1994. A subcloned ribosoma RNA probe for bacterial ribotype analysis. J. Infect. Dis. 169:1413-1414.

17. Musser, J. M., D. A. Bemis, H. Ishikawa, and R. K. Selander. 1987. Clonal diversity and host distribution in Bordetella bronchiseptica. J. Bacteriol. 169: 2793-2803.

18. Musser, J. M., E. L. Hewlett, M. S. Peppler, and R. K. Selander. 1986. Genetic diversity and relationships in populations of Bordetella spp. J. Bacteriol. 166:230-237.

19. Pedersen, K. B. 1975 . The serology of Bordetella bronchiseptica isolated from pigs compared with strains from other animal species. Acta Pathol. Microbiol. Scand. 83:590-594.

20. Peppler, M. S., and M. E. Schrumf. 1984. Phenotypic variation and modulation in Bordetella bronchiseptica. Infect. Immun. 44:681-687.

21. Porter, J. F., R. Parton, and A. C. Wardlaw. 1991. Growth and survival of Bordetella bronchiseptica in natural waters and in buffered saline without added nutrients. Appl. Environ. Microbiol. 57:1202-1206.

22. Porter, J. F., and A. C. Wardlaw. 1993. Long-term survival of Bordetella bronchiseptica in lakewater and in buffered saline without added nutrients. FEMS Microbiol. Lett. 110:33-36.

23. Ross, R. F., W. P. Switzer, and J. R. Duncan. 1967. Comparison of patho- 
genicity of various isolates of Bordetella bronchiseptica in young pigs. Can. J. Comp. Med. Vet. Sci. 31:53-57.

24. Selander, R. K., D. A. Caugant, H. Ochman, J. M. Musser, M. N. Gilmour, and T. S. Whittam. 1986. Methods of multilocus enzyme electrophoresis for bacterial population genetics and systematics. Appl. Environ. Microbiol. 51: $873-884$.

25. Selander, R. K., R. M. McKinney, T. S. Whittam, W. F. Bibb, D. J. Brennan, F. S. Nolte, and P. E. Pattison. 1985. Genetic structure of populations of
Legionella pneumophila. J. Bacteriol. 163:1021-1037.

26. Southern, E. M. 1975. Detection of specific sequences among DNA fragments separated by gel electrophoresis. J. Mol. Biol. 98:503-517.

27. Stull, T. L., J. J. LiPuma, and T. D. Edlind. 1988. A broad-spectrum probe for molecular epidemiology of bacteria: ribosomal RNA. J. Infect. Dis. 157 280-286.

28. Woolfrey, B. F., and J. A. Moody. 1991. Human infections associated with Bordetella bronchiseptica. Clin. Microbiol. Rev. 4:243-255. 